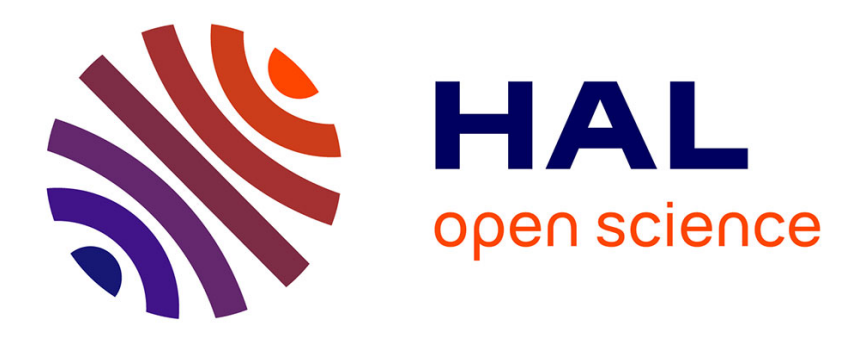

\title{
Sensitivity and feeding efficiency of the black garden ant Lasius niger to sugar resources \\ Claire Detrain, Jacques Prieur
}

\section{To cite this version:}

Claire Detrain, Jacques Prieur. Sensitivity and feeding efficiency of the black garden ant Lasius niger to sugar resources. Journal of Insect Physiology, 2014, 64, pp.74 - 80. 10.1016/j.jinsphys.2014.03.010 . hal-01016466

\section{HAL Id: hal-01016466 \\ https://hal.science/hal-01016466}

Submitted on 30 Jun 2014

HAL is a multi-disciplinary open access archive for the deposit and dissemination of scientific research documents, whether they are published or not. The documents may come from teaching and research institutions in France or abroad, or from public or private research centers.
L'archive ouverte pluridisciplinaire HAL, est destinée au dépôt et à la diffusion de documents scientifiques de niveau recherche, publiés ou non, émanant des établissements d'enseignement et de recherche français ou étrangers, des laboratoires publics ou privés. 


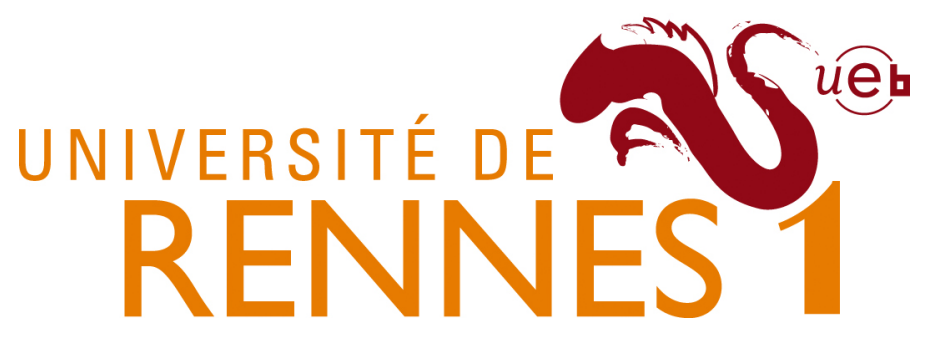

\title{
Sensitivity and feeding efficiency of the black garden ant Lasius niger to sugar resources
}

\author{
Claire Detrain $^{\mathrm{a}, *}$, Jacques Prieur ${ }^{\mathrm{b}}$ \\ ${ }^{a}$ Service d'Ecologie Sociale CP 231, Université Libre de Bruxelles, 50 avenue F. Rossevelt, B-1050 Bruxelles, Belgium \\ ${ }^{\mathrm{b}}$ UMR 6552 ETHOS, University of Rennes 1, CNRS Biological Station, 35380 Paimpont, France
}

\begin{abstract}
A B S T R A C T
Carbohydrate sources such as plant exudates, nectar and honeydew represent the main source of energy for many ant species and contribute towards maintaining their mutualistic relationships with plants or aphid colonies. Here we characterise the sensitivity, feeding response curve and food intake efficiency of the aphid tending ant, Lasius niger for major sugars found in nectar, honeydew and insect haemolymph (i.e. fructose, glucose, sucrose, melezitose and trehalose). We found that sucrose concentrations - ranging from 0.1 to $2.5 \mathrm{M}$ - triggered food acceptance by L. niger workers with their food intake efficiency being enhanced by sugar concentrations of $1 \mathrm{M}$ or higher at which points energy intake was maximised. The range of sucrose concentrations that elicit a feeding response by $L$. niger scouts thus overlaps with that of natural sugar resources. The response curves of feeding acceptance by scouts consistently increased with sugar concentration, except for trehalose which was disregarded by the ants. Ants are highly sensitive to sucrose and melezitose exhibiting low response thresholds. Sucrose, fructose and glucose share a same potential to act as phagostimulants as they had similar half feeding efficiency concentration values when expressed as the energetic content of sugar solution. Aphid-biosynthezised melezitose generated the highest sensitivity and phagostimulant potential. The feeding behavior of ants appears to be primarily regulated by the energy content of the food solution for the main sugars present in nectar and honeydew. However, feeding by scouts is also influenced by the informative value of individual sugars when it serves as a cue for the presence of aphid partners such as the aphid-biosynthesised melezitose.
\end{abstract}

\section{Introduction}

Sugary resources are widespread in the environment with examples including aphid honeydew, extrafloral and floral nectar, phloem and xylem sap and fruit pulp. However, the abundance, concentration, spatial distribution and degree of accessibility of these resources are highly heterogeneous. Honeydew and nectar are composed of monosaccharides and oligosaccharides (e.g. Percival, 1961; Völkl et al., 1999; Wäckers, 2001), in addition to small amounts of other chemical compounds such as amino acids, proteins and lipids (Baker and Baker, 1973; Gonzalez-Teuber and Heil, 2009; Lanza et al., 1995). Nectar tends to have a rather restricted breadth of sugars available to visitors and is primarily dominated by the disaccharide sucrose and its hexose components, fructose and glucose (Buckley, 1987; Gonzalez-Teuber and Heil, 2009; Heil, 2011; Lanza et al., 1995; Percival, 1961). In comparison, honeydew usually contains a more diverse carbohydrate profile. Indeed, the

\footnotetext{
* Corresponding author. Tel.: +32 650.55.29; fax: +32 26505987 .

E-mail address: cdetrain@ulb.ac.be (C. Detrain).
}

bulk of aphid excreta is mainly composed of sucrose, fructose and glucose but also contains variable amounts of trehalose and melezitose, with the latter trisaccharide being biosynthesised by the aphids (Detrain et al., 2010; Fischer et al., 2005; Fischer and Shingleton, 2001; Vantaux, 2011; Völkl et al., 1999; Wäckers, 2000; Yao and Akimoto, 2001).

Many arthropods - even carnivorous ones - are attracted to these sugar meals and have evolved physiological and neuronal mechanisms to detect and ingest carbohydrates as the main source of energy. Consequently, ants are ubiquitous and regular visitors of plant nectar and honeydew produced by aphids of which sugar content is very important for the initiation and maintenance of mutualistic relationships (Beattie, 1985; Blüthgen and Fiedler, 2004; Buckley, 1987; Engel et al., 2001; Stadler and Dixon, 2005; Way, 1963). The ecological dominance of ants is strongly linked to the flexibility of their foraging strategies. For instance, ants may adjust their feeding behaviour and the intensity of food recruitment according to the energetic and metabolic value of carbohydrate sources such as the amount and/or chemical composition of food (e.g. Detrain et al., 1999, 2010; Dussutour and Simpson, 2008; 
Hölldobler and Wilson, 1990; Jackson and Châline, 2007; Mailleux et al., 2000, 2003; Völkl et al., 1999).

A diversity of sugary resources is available to ants, thus scouts should have evolved physiological abilities to feed preferentially on the most profitable sugars. For a sugar to be a suitable meal, it must first be detected and then elicit a feeding response among ant foragers. Not all sugars are phagostimulatory. For instance, maltose, xylose, melibiose only elicit a weak feeding response (Boevé and Wäckers, 2003; Detrain et al., 2010). In contrast, four sugars (i.e. melezitose, sucrose, fructose and glucose) are regularly consumed by the majority of ants, even though species-specific sugar preferences have been demonstrated (Blüthgen and Fiedler, 2004; Völkl et al., 1999). Previous studies have established a hierarchy of sugar preferences by comparing the global foraging effort made by the whole colony based on the total amount of ingested food and/or the resulting flows of foragers (Tinti and Nofre, 2001; Völkl et al., 1999). Surprisingly, information remains limited at the level of the ant individual, even though the feeding response of scouts is the cornerstone upon which food recruitment is built. Furthermore, because ant responses were usually measured for just one sugar concentration, knowledge remains limited about how glucophagy by the ant individuals that discover the food source evolves for increasing sugar concentrations. Dose-response curves are only well-established for sucrose: previous studies have quantified the propensity of foragers to recruit nestmates (Beckers et al., 1993; Detrain et al., 1999; Dussutour and Simpson, 2008; Jackson and Châline, 2007; Wilson, 1962) along with several feeding variables, such as food acceptance, crop load, feeding time and ingestion rates (Dussutour and Simpson, 2008; Faribele and Josens, 2012; Josens et al., 1998; Josens and Roces, 2000). In contrast, the feeding response curves of ants remain unknown for the other sugars that are commonly found in nectar and honeydew. Yet, data about dose-feeding response curves are essential to assess the sensory and physiological abilities of scout individuals. Such information would contribute towards understanding how ant species have evolved a feeding behavior that is adapted to the energetic and ecological value of natural sugar resources.

Here, we investigate whether the main sugars produced by plants and aphids differ in their ability to elicit a feeding response among Lasius niger ants and how the feeding responses of scouts change for a wide range of sugar concentrations. We selected the black garden ant $L$. niger as the biological model to study sugar perception and feeding because this ant species is a regular visitor of both aphid colonies and plant nectar (Engel et al., 2001). Furthermore, we investigate how the ingestion rate and feeding efficiency of this aphid-tending species change in response to increasing amounts of sucrose for comparisons with existing data on other sugar-consuming ants. This research provides an interpretative physiological framework to improve our understanding about how ants forage on sugary resources and develop mutualistic relationships with aphids and plants.

\section{Material and methods}

\subsection{Collection and rearing of colonies}

Experiments were carried out on the black garden ant, L. niger, a common aphid-tending species in European temperate regions. Four colonies of about 1000 ants were collected in Brussels and placed in plastic containers of which edges were covered with polytetrafluoroethylene (Fluon ${ }^{\circledR}$ ) to prevent ants from escaping. Test tubes covered with a red transparent foil were used as rearing nests in the laboratory. Aqueous sucrose solution (1 M) and water filled test tubes were provided ad libitum. Twice a week, dead insects (cockroaches or fruit flies) were added as protein sources.
Colonies were kept in controlled conditions of hygrometry $(65 \pm 5 \%$ ), luminosity (Light-Dark: $16: 8 \mathrm{~h}$ ) and temperature $\left(20 \pm 2{ }^{\circ} \mathrm{C}\right)$.

\subsection{Experimental procedure}

Behaviour of $L$. niger scouts were compared when faced with sugar solutions differing by their nature and concentration. All tested concentrations were made by dissolving sugars of high purity (at least 99\% purity Fluka Analyticals Sigma-Aldrich) into pure distilled water. The following sugars were tested:

D-Glucose and D-fructose: two monosaccharides that are commonly found in fruits, nectars and aphid honeydew (Fischer and Shingleton, 2001; Percival, 1961).

Sucrose: a disaccharide made of D-glucose and D-fructose units that is widespread in nectar and aphid honeydew (Fischer and Shingleton, 2001; Percival, 1961).

Melezitose, a trisaccharide including two D-glucose units and one D-fructose unit, that is scarcely found in plant-originating sugars but frequently excreted by aphids in their honeydew (Fischer and Shingleton, 2001; Vantaux et al., 2011; Wäckers 2000, 2001).

Trehalose, a disaccharide of two D-glucose units that is known as an energy storage compound in the haemolymph of several insect species (Turunen, 1985).

Increasing concentrations were made until reaching the limit of solubility of each sugar. For each sugar, we tested the following concentrations $0.001 ; 0.01 ; 0.1 ; 0.5 ; 1$ and $2.5 \mathrm{M}$. Since melezitose and trehalose were less soluble sugars, we could not test the highest $2.5 \mathrm{M}$ concentration. All sugar solutions were stored at $+5^{\circ} \mathrm{C}$ and left at ambient temperature for $1 \mathrm{~h}$ before starting the experiments. Before each experimental session, ant colonies were deprived of food but allowed water for three days.

The first experiment assessed how the energetic return drawn by the ants from a sugar solution was influenced by its concentration in carbohydrates. We chose sucrose as a reference sugar to investigate how concentration influenced food intake as previously done for other ant species (in the genus Camponotus (Faribele and Josens, 2012; Josens et al., 1998; Josens and Roces, 2000), Rhytidoponera (Dussutour and Simpson, 2008), Linepithema, Cephalotes and Acromyrmex (Faribele and Josens, 2012)). We compared the feeding response of $L$. niger scouts over a range of sucrose concentrations; specifically, $0.001,0.01,0.1,0.5,1$ and $2.5 \mathrm{M}$. Groups of five $L$. niger scouts were randomly taken out of the foraging arena of one colony and allowed to explore the experimental set-up during $5 \mathrm{~min}$. The experimental-setup consisted in a Petri dish $(9 \mathrm{~cm}$ in diameter) in the center of which a bowl-shaped feeder ( $3.8 \mathrm{~cm}$ in diameter) was placed. At the end of this exploration phase, a ring ( $4 \mathrm{~cm}$ diameter) was placed around the feeder in order to prevent ants from accessing the feeder while filling it up with $500 \mu \mathrm{l}$ of the tested sugar solution. The experiment began when the ring was removed. For each concentration, we video recorded the behaviour of ants around the sucrose droplet and we measured the total time spent feeding by all of the ants. We placed all of the ants into a small vial before and after the experiment to measure the initial and final body weight of each experimental group (Mettler ${ }^{\mathrm{TM}}$ balance, nearest $0.01 \mathrm{mg}$ ). This measurement enabled us to estimate the average crop load after feeding on a sucrose droplet as well as the rate of sugar ingestion for each concentration. Three colonies were tested twice for each sucrose concentration (6 replicates in total per tested concentration). Each colony and each sugar concentration were tested in a random order.

The second experiment assessed the feeding response curves of L. niger ants faced to water or to increasing concentrations $(0.001$, $0.01,0.1,0.5,1$ and $2.5 \mathrm{M}$ ) of a single sugar. This experiment was done for sucrose, fructose, glucose, melezitose and trehalose. 
However, the two last sugars were not assessed at $2.5 \mathrm{M}$ because of their limit of solubility. The experimental-setup and procedure were the same as in the first experiment. Groups of 15 scouts were randomly taken out of the foraging arena of one colony. The experiment began when the ring was removed: the behaviour of ants approaching and feeding at the food source was then recorded for 15 min using a video camera (Panasonic; magnification $\times 8$ ).

The perception and feeding responses of ants were assessed for each sugar solution using three variables: (1) the total number of times that ants made antennal contacts with the sugar solution without dipping their mandibles into the food, (2) the total number of feeding events made by ants that immersed their mandibles into the sugar solution and (3) the feeding acceptance index, which is defined as the ratio between the total number of feeding events and the total number of contacts with food (i.e. the sum of antennal contacts with food and feeding events).

After the experiment, the scouts were removed from the experimental setup and temporarily separated from their colony to prevent them from doing trophallaxies and consequently modifying the starvation level of nestmates during the experiment. The experimental setup and the feeder were washed with alcohol between each trial to prevent any bias caused by the possible chemical marking of the substrate by fed foragers. At the end of each experimental session, the ants were returned to their colony. Seven replicates were made for each concentration of each sugar.

\subsection{Data analyses}

Changes in the efficiency of sugar intake were investigated for increasing concentrations of sucrose solution. The total food weight ingested by a group of five ants was divided by the cumulated total time spent by these five scouts feeding at the sucrose solution. This ratio provides an estimate of sugar intake per time unit. Because these ratios did not meet normality assumptions, they were analysed by non-parametric statistical tests. Subsequently to a rank-transformation procedure, a Friedman's twoway analysis of variance was performed on the sugar intake rate to test for diet effect and group effect by coding either the sugar concentration or the mother colony of tested scouts as fixed factors. Because we found that group had no significant effect on food intake rate (Friedman test: $F_{5,25}=1.3, \mathrm{NS}$ ), the data from all groups were concurrently evaluated in all subsequent analyses. The intake rates for different sucrose concentrations were compared by nonparametric Kruskal-Wallis test, followed by the post hoc Dunn test.

The feeding responses of $L$. niger workers on different naturally occurring sugars were estimated by their feeding acceptance index. For each sugar and each molar concentration, the percentage of contacts with food followed by a feeding event within each group of 15 scouts was measured for each replicate. We then compiled dose-feeding acceptance curves for increasing concentrations of sucrose, melezitose, fructose, glucose and trehalose. The curves of all sugars, except trehalose fitted the following equation, which commonly describes the functional response characterising an agonist-receptor binding complex:

$A=A_{\min }+\left(A_{\max }-A_{\min }\right) /\left(1+10^{\wedge}\left(\operatorname{LogEC}_{50}-\log \mathrm{C}\right)\right)$

where $A$ is the observed feeding acceptance response and $A_{\min }$ is the minimal feeding acceptance shown by the ants in response to a water droplet (i.e. a droplet without sugar). For curve fitting, $A_{\text {min }}$ was fixed at a value of 0.024 , which is the average feeding acceptance shown by ants drinking on a water droplet (value averaged across all replicates).

$A_{\max }$ is the maximal feeding acceptance extrapolated from the curve fitting of ant response for the highest sugar concentrations.
$A_{\max }$ accounts for the maximal affinity that ants are expected to show for a given sugar.

$\mathrm{EC}_{50}$ is the half feeding efficiency representing the sugar concentration at which $50 \%$ of ants that came into contact with food showed a feeding response. Low $\mathrm{EC}_{50}$ values characterise sugars with high phagostimulant efficiency because these sugars are fed upon by ant workers even at weak concentrations.

By best-fitting each dose-feeding response curve, we then extracted the $\mathrm{EC}_{50}$ and $A_{\max }$ values that were specific to each sugar. The first $\mathrm{EC}_{50}$ value reflects the phagostimulatory effect of one sugar and the second $A_{\max }$ value accounts for the maximal willingness of ants to feed upon it.

We used the GraphPad Prism 5 software to fit ant feeding responses to increasing sugar concentrations and to extract the values of curve parameters' values and their associated standard errors. For each of these curve parameters (i.e. $A_{\max }$ and Log $\mathrm{EC}_{50}$ ), comparisons between sugars were made using $t$-tests.

For each sugar, we also identified a threshold concentration (TC) along its best-fitted curve. This threshold value is defined as the sugar concentration where the feeding acceptance response exceeds the upper limit of the $95 \%$ confidence interval obtained for water drinking - i.e. a value of feeding acceptance equal to 0.074 . Because this threshold value was inferred a posteriori from the fitting of the response curve to one sugar and from the upper confidence limit of water acceptance, there was no associated standard deviation. This lack of variability value prevented testing the statistical significance of TC differences between sugars.

All tests were two-tailed with the significance level being set at $\alpha=0.05$. All average values were provided with standard deviations.

\section{Results}

\subsection{Influence of sugar concentration on food intake rate}

For sucrose concentrations lower than $0.01 \mathrm{M}$, all ants made a high number of contacts before deciding to feed on the droplet. Some of the ants drank only a little food with their feeding times lasting less than $5 \mathrm{~s}$ on average. Feeding behaviour at these weak sugar concentrations was similar to when ants drank water (Table 1). Workers seemed to perceive sucrose at a $0.01 \mathrm{M}$ droplet. In fact, ants were less hesitating to feed on the droplet, making fewer contacts before starting to drink and showed twice more feeding events compared to water However, at this weak $0.01 \mathrm{M}$ sugar concentration, drinking behaviour remained brief, lasting less than $5 \mathrm{~s}$. The willingness of ants to feed markedly increased at sucrose concentrations equal to or higher than $0.1 \mathrm{M}$ with feeding being usually released just after their first contact with the droplet. At a concentration of $0.1 \mathrm{M}$ sucrose, the majority of ants drank for less than $1 \mathrm{~min}$ (Table 1, Fig. 1). A further increase in sucrose concentration $(0.5 \mathrm{M}$ and $1 \mathrm{M})$ resulted in ants feeding for up to 20 times longer (Table 1). For the most concentrated solution $(2.5 \mathrm{M})$, ants drank for more than $3 \mathrm{~min}$ on average. At each sugar concentration, there was a wide interindividual variability in drinking times. For instance, a few scouts fed for less than $10 \mathrm{~s}$ on $1 \mathrm{M}$ solution while others ingested food for more than $3 \mathrm{~min}$ (Fig. 1). A pronounced shift towards longer drinking duration was noticeable at $2.5 \mathrm{M}$ sucrose solution. This rise was probably due to a higher viscosity of the solution which decelerated food ingestion with some individuals drinking for more than 5 min (Fig. 1).

To assess the feeding efficiency of ant workers, the sugar (energy) intake per unit time (expressed in $\mathrm{mg} / \mathrm{min}$ ) was calculated for increasing concentrations of sucrose solutions (Fig. 2). There was no significant group effect on sugar intake rate (Friedman test: $F_{5,25}=1.3$, NS) but a significant effet of sugar concentration (Friedman test: $F_{5,25}=379, P<0.001$ ). Like that recorded by 
Table 1

Feeding parameters (mean \pm SE) of ants that came into contact with a sucrose droplet. For increasing sucrose concentration, we measured the number of feeding events, their duration and the number of contacts with the droplet before the ant started to drink. Sample size values (i.e. the number of ants having contacted at least once the droplet) are presented in parentheses. All values were compared by the non-parametric Kruskal-Wallis test followed by post-hoc multiple comparison tests (Dunn test). Values sharing at least one superscript letter were not significantly different.

\begin{tabular}{|c|c|c|c|}
\hline & $\mathrm{N}$ contacts before feeding & $\mathrm{N}$ feeding events & Duration of first feeding event (s) \\
\hline Water & $4.62 \pm 1.10^{\mathrm{a}}(24)$ & $1.37 \pm 0.15^{\mathrm{a}}(24)$ & $4.45 \pm 0.9^{\mathrm{a}}(22)$ \\
\hline $10^{-3}$ M Sucrose & $4.57 \pm 0.79^{\mathrm{a}}(28)$ & $1.25 \pm 0.17^{\mathrm{abd}}(28)$ & $3.75 \pm 0.6^{\mathrm{a}}(24)$ \\
\hline $10^{-2} \mathrm{M}$ Sucrose & $2.81 \pm 0.58^{\text {abd }}(27)$ & $3.26 \pm 0.63^{\text {bcd }}(27)$ & $4.4 \pm 0.8^{\mathrm{a}}(25)$ \\
\hline $10^{-1} \mathrm{M}$ Sucrose & $1.25 \pm 0.08^{\mathrm{bc}}(28)$ & $6.25 \pm 0.68^{\text {ce }}(28)$ & $29.7 \pm 5.1^{\mathrm{b}}(28)$ \\
\hline 0.5 M Sucrose & $1.22 \pm 0.08^{\mathrm{bc}}(27)$ & $8.0 \pm 0.77^{\mathrm{ef}}(27)$ & $73.2 \pm 7.1^{\mathrm{bc}}(27)$ \\
\hline 1 M Sucrose & $1.09 \pm 0.06^{\mathrm{c}}(22)$ & $5.27 \pm 0.76^{\mathrm{fc}}(22)$ & $85.7 \pm 12.6^{\mathrm{bc}}(21)$ \\
\hline $2.5 \mathrm{M}$ Sucrose & $1.19 \pm 0.08^{\mathrm{cd}}(27)$ & $1.59 \pm 0.18^{\mathrm{d}}(27)$ & $215.6 \pm 12.5^{\mathrm{c}}(27)$ \\
\hline Test & Kruskal Wallis $P<0.0001$ & Kruskal Wallis $P<0.0001$ & Kruskal Wallis $P<0.05$ \\
\hline
\end{tabular}

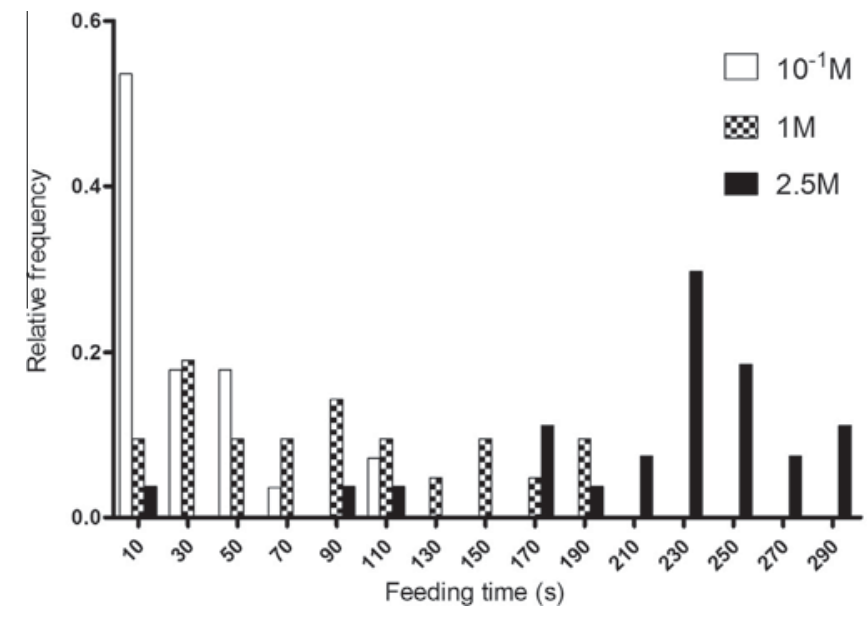

Fig. 1. Frequency distribution of individual feeding times shown by Lasius niger scouts that first contacted the droplet. Droplets with different concentrations of sucrose were tested $(0.1 \mathrm{M}, n=28),(1 \mathrm{M}, n=21)$ and $(2.5 \mathrm{M}, n=27)$. For weakly concentrated solutions $(<0.01 \mathrm{M})$, all drinking times were shorter than $10 \mathrm{~s}$.

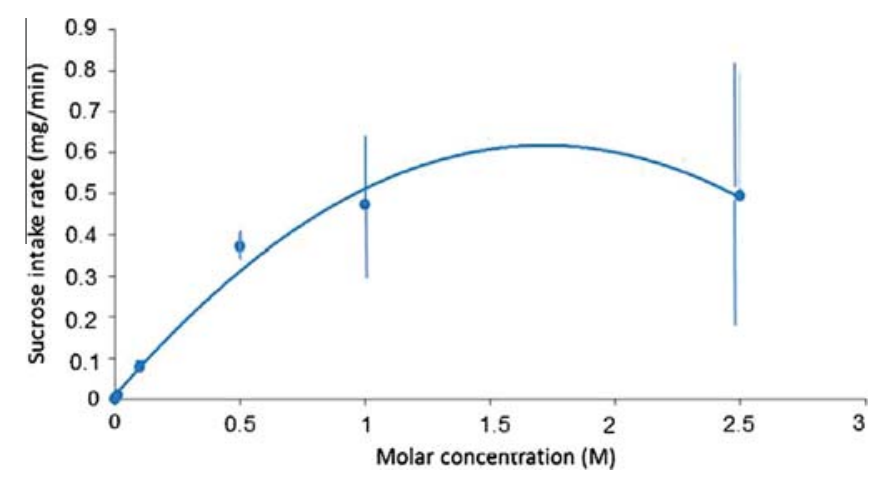

Fig. 2. Intake rate of sucrose solution as a function of its molar concentration. The intake rate was measured for groups of five L. niger scouts and expressed in mg sucrose ingested per minute (mean \pm standard deviation). Based on previous studies on ants' feeding behaviour (Josens et al. (1998)), we chose a quadratic function to best-fit our data The best-fitted curve follows the equation $y=-0.2075 x^{2}+0.711 x+0.0086 ; R^{2}=0.984$.

Josens et al., (1998), the sugar intake rate significantly changed as a function of the molar concentration of the sugar droplet (KruskalWallis' test; $N=6 ; K=29.98, P<0.001$ ). We observed a significanly lower intake rate of just $0.002 \mathrm{mg} / \mathrm{min}$ on average for $0.001 \mathrm{M}$ solution compared to higher concentrations (Dunn's test; for $0.5 \mathrm{M}: P<0.01$; for $1 \mathrm{M}: P<0.001$; for $2.5 \mathrm{M}: P<0.001)$, in addition to a lower intake rate of just $0.008 \mathrm{mg}$ sugar/min for $0.01 \mathrm{M}$ solution compared to the two highest tested concentrations (Dunn's test; $1 \mathrm{M}: P<0.05 ; 2.5 \mathrm{M}: P<0.05)$. For sucrose solutions of $1-2.5 \mathrm{M}$ maximum food intake values of around $0.5 \mathrm{mg}$ sucrose ingested per minute were obtained.

\subsection{Influence of the type and concentration of sugar on feeding acceptance by L. niger scouts}

Regardless of the tested sugar, the acceptance of a sugar droplet statistically differed according to its molar concentration, (Kruskal-Wallis test: Sucrose: $\mathrm{KW}=41.27, P<0.0001$; Melezitose: $\mathrm{KW}=34.09, P<0.0001$; Fructose: $\mathrm{KW}=47.75, P<0.0001$; Glucose: $\mathrm{KW}=39.26, P<0.0001$; Trehalose: $\mathrm{KW}=13.09, P<0.05$ ). For each tested sugar, workers rarely ingested food at the lowest tested concentration $(0.001 \mathrm{M})$. This minimal feeding acceptance probably reflected water drinking by thirsty individuals. As molarity increased, the scouts fed more eagerly on each sugar solution. The only exception was trehalose for which the feeding response remained comparatively low, even at the highest tested concentration, with a maximal feeding acceptance of 0.09 at $1 \mathrm{M}$ solution. Because of the very weak response of ants, the curve for trehalose could not be confidently fitted. For all of the other tested sugars, the feeding acceptance curves (Fig. 3a-d) were well fitted by response threshold curves. By choosing to fit all data sets with the same type of log dose-response relationship, it is possible to differentiate the feeding response of ants to sugars by comparing their specific values of threshold concentration (TC), maximal feeding acceptance $\left(A_{\max }\right)$ and half efficiency concentration $\left(\mathrm{EC}_{50}\right)$. It was found that $L$. niger was highly sensitive to melezitose with a weak threshold concentration of $0.014 \mathrm{M}$. A threshold of double this molarity was required for sucrose $(0.03 \mathrm{M})$ to obtain a significant feeding response. Ants were even less sensitive to the two tested monosaccharides - (glucose and fructose) - with a threshold of around $0.08 \mathrm{M}$ being required for the solutions to be detected by ants. Because the number of saccharidic units differed in the tested sugars, the threshold concentration (TC values) of feeding acceptance should also be expressed in terms of sugar mass per $g$ of solvent. Even though between-sugar differences were lower when using mass concentration, the same trend of decreasing threshold concentration was maintained, with the sugars being ordered: fructose $=$ glucose $>$ sucrose $>$ melezitose (Table 2). Ants remained more sensitive to very low amounts of melezitose and sucrose with just $0.01 \mathrm{~g}$ sugar/ml being sufficient to stimulate a feeding acceptance higher than drinking water.

The maximal feeding acceptance $\left(A_{\max }\right)$ and the half efficiency concentration $\left(\mathrm{EC}_{50}\right)$ reflect the phagostimulating potential of each sugar (Table 2). Sucrose and fructose were the sugars for which maximal values of feeding acceptance index $\left(A_{\max }\right)$ were the highest and were similar for both sugars ( $t$-test: Sucrose-Fructose: $t_{0.05(2) 89}=0.46$, NS). At highly concentrated sucrose and fructose solutions, more than a third of contacts $(0.36-0.37)$ were followed 

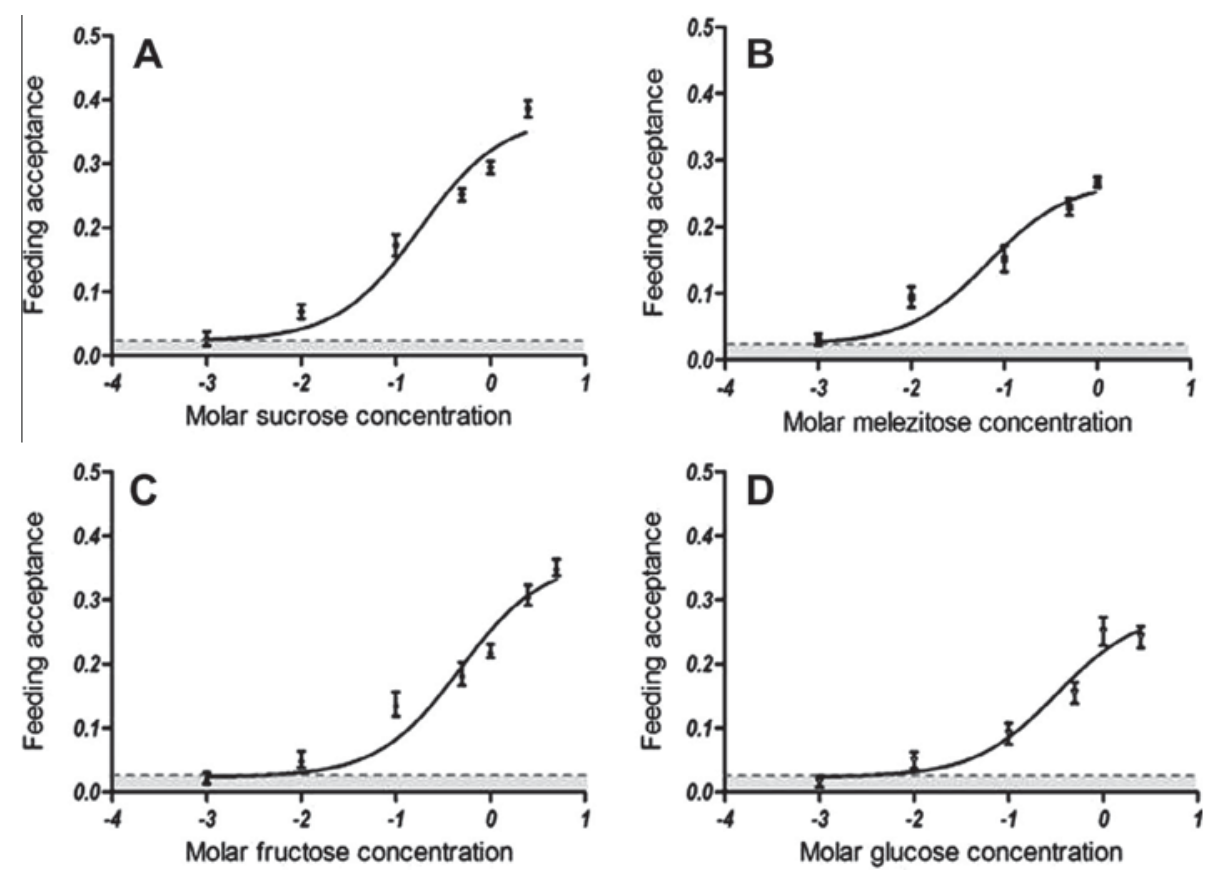

Fig. 3. Feeding acceptance (mean \pm standard deviation, $n=7$ ) as a function of molar concentration for sucrose (A), melezitose (B), fructose (C) and glucose (D). The shaded area represents the upper limit of the $95 \%$ confidence interval obtained for drinking water. This limit generates the response threshold (TC) which is the sugar concentration at which feeding acceptance starts to exceed water drinking. Data were best-fitted by threshold curves of which parameters are presented in Table 2 . Because of the very weak response of ants, the curve for trehalose could not be confidently fitted.

Table 2

Fitting parameters of ant feeding response curves for each tested sugar. By using the standard errors associated to each $A_{\max }$ and Log EC $\mathrm{C}_{50}$ values, we compared these parameters between different sugars by using $t$-tests (significance level $=0.05$ ). For a given fitting parameter, values sharing at least one superscript letter were not significantly different.

\begin{tabular}{llll}
\hline Fitting parameters & Melezitose & Sucrose & Flucose \\
\cline { 2 - 4 } & $N=35$ & $N=42$ & $N=42$ \\
\hline$R^{2}$ & 0.82 & 0.91 & 0.80 \\
TC in molar concentration & $0.014 \mathrm{M}$ & $0.03 \mathrm{M}$ & $0.078 \mathrm{M}$ \\
TC in mass concentration (\%) & $0.7 \%$ & $1 \%$ & 0.86 \\
$A_{\min }$ & 0.024 & 0.024 & $0.083 \mathrm{M}$ \\
$A_{\max }$ & $0.268^{\mathrm{a}}$ & $0.373^{\mathrm{b}}$ & 0.024 \\
EC $_{50}$ in molar concentration & $0.054 \mathrm{M}^{\mathrm{a}}$ & $0.179 \mathrm{M}^{\mathrm{b}}$ & $0.283^{\mathrm{c}}$ \\
EC50 $^{\mathrm{b}}$ in mass concentration (\%) & $2.7 \%^{\mathrm{a}}$ & $6 \%^{\mathrm{b}}$ & $0.322 \mathrm{M}^{\mathrm{bc}}$ \\
\hline
\end{tabular}

by drinking behavior. For melezitose and glucose, only a $0.27-0.28$ maximal acceptance rate was induced among ants that encountered the food droplet, which was significantly lower compared to that recorded for sucrose ( $t$-test: Sucrose-Melezitose: $t_{0.05(2) 75}=4.99, \quad P<0.001 ;$ Sucrose-Glucose: $t_{0.05(2) 82}=3.06, \quad P<$ $0.005)$ and for fructose ( $t$-test: Fructose-Melezitose: $t_{0.05(2) 82}=$ 3.76, $P<0.001$; Fructose-Glucose: $\left.t_{0.05(2) 89}=2.48, P<0.05\right)$. To reach the half of maximal feeding acceptance, melezitose had the strongest phagostimulating potential, with an $\mathrm{EC}_{50}$ value of just $0.054 \mathrm{M}$ (t-test: Melezitose-Sucrose: $t_{0.05(2) 75}=3.25, P<0.005$; Melezitose-Glucose: $t_{0.05(2) 75}=3.76, P<0.001$; Melezitose-Fructose: $\left.t_{0.05(2) 82}=5.86, P<0.001\right)$. Sucrose also had a higher phagostimulating efficiency $\left(\mathrm{EC}_{50}=0.179\right)$ compared to the two monosaccharides, glucose and fructose $\left(\mathrm{EC}_{50}=0.322 \mathrm{M}\right.$ and $0.48 \mathrm{M}$, respectively) (significant difference only for sucrose VS fructose $\left(t_{0.05(2) 89}=3.16, P<0.05\right)$ but not for sucrose VS glucose $\left.\left(t_{0.05(2) 82}=1.44, \mathrm{NS}\right)\right)$. When expressed in energetic content, melezitose was confirmed to be the highest phagostimulant, because it had a half feeding efficiency with the lowest sugar amount of $2.7 \%$ sugar/g solvent ( $t$-test on mass concentration: Melezitose-Sucrose: $t_{0.05(2) 75}=2.29, P<0.05$; Melezitose-Glucose: $t_{0.05(2) 75}=2.0$, $P<0.05$; Melezitose-Fructose: $\left.t_{0.05(2) 82}=2.76, P<0.01\right)$.

\section{Discussion}

Ants are exposed to a diversity of natural carbohydrate resources that differ in total amounts of sugars, concentration and composition as well as in energetic value. Consequently, ants have evolved chemosensory and behavioural traits to detect, exploit and monopolise the most valuable sugar producers efficiently. In this respect, the feeding response of foragers to sucrose is a widelyused and reliable indicator of the motivation of ants to exploit sugary resources (Faribele and Josens, 2012; Josens and Roces, 2000).

Chemosensory inputs provided by sucrose molecules on the antennae or labial palps of insects regulate their feeding behaviour, as shown for honeybees (Page et al., 1998; Pankiw and Page, 1999; Pankiw et al., 2001) and some ant species (Faribele and Josens, 2012; Josens et al., 1998; Josens and Roces, 2000; Perez et al., 2013). This chemosensory hypothesis was supported by our data because we demonstrated that sucrose concentration modulated feeding acceptance, feeding time and food intake rate of $L$. niger ants. There is a "critical" concentration of sucrose chemoperception at which the feeding behavior of ants is stimulated by the presence of sugar molecules, as demonstrated by the increase in the number of feeding events at a concentration of $0.01 \mathrm{M}$ solution. 
Meanwhile, there was a decrease in the number of antennal contacts with food before the ants decided to drink. This increased likelihood to feed on food with higher sucrose concentration probably reflected the better chemoperception of sugars by the gustatory receptors of the ants. Our results support the study of Tinti and Nofre (2001), in which L. niger workers only fed on sucrose concentrations higher than $0.005 \mathrm{~g} / \mathrm{ml}$ (i.e. $0.0146 \mathrm{M}$ ).

Beyond this first "critical" perception threshold, a further increase in sucrose content (higher than $0.1 \mathrm{M}$ ) enhanced the interest of ants and extended the duration of drinking per feeding event. The interindividual variability of feeding times might be explained by differences in the gustatory sensitivity of individual scouts to carbohydrates or in their sucking efficiency on liquid food. We found that sucrose concentrations ranging from 0.1 to $1 \mathrm{M}$ induced a steep increase in the food intake rate by L. niger workers. This result supports previous studies, which showed an increase of food intake for sugar mass concentrations ranging from $3 \%$ to $30 \% \mathrm{w} / \mathrm{w}$ (i.e. from $0.1 \mathrm{M}$ to $1 \mathrm{M}$ ) in other ant species that regularly tend aphids (Camponotus mus, Josens et al., 1998; Camponotus rufipes, Paul and Roces, 2003) or that occasionally feed on nectar, such as predatory ants (Rhytidoponera metallica, Dussutour and Simpson, 2008) and leaf cutting ants (Atta sexdens, Paul and Roces, 2003).

At even higher concentrations, the food intake rate of droplets stabilized, because of the higher motivation of $L$. niger ants to feed on sugars is counterbalanced by physical constraints on ingestion caused by the exponential increase of fluid viscosity above a concentration of 1.5 M sucrose (Josens et al.,1998). Unlike licking ants that repeatedly extend their glossa to drive food into the mouth, the intake rates of fluid-sucking ants, such as $L$. niger, depend on the activity of the pharyngeal pump and the morphometrics of the alimentary canal (Josens and Roces, 2000; Paul and Roces, 2003). The existence of a concentration at which the fluid intake rate becomes negatively affected by viscosity has already been reported for other honeydew feeding ants (Josens et al., 1998; Paul and Roces, 2003), as well as for most bee species, including bumblebees, which have the highest energy intake rate at high concentrations of 60\% (Harder, 1986; Nardone et al., 2013; Roubik and Buchmann, 1984).

Sugar intake rate by $L$. niger workers becomes maximal in the same range of $30-40 \% \mathrm{w} / \mathrm{w}$ sucrose droplet (i.e. $1-1.3 \mathrm{M}$ ) as documented for other ant species (Josens et al., 1998; Paul and Roces, 2003). Therefore, our results support the concept that variable sucrose concentrations have a broadly similar impact across ant species that share similar feeding mechanics. From a functional and ecological perspective, sucrose intake by ants increases within the range of concentrations found in natural sugar resources. The sugar content of aphid honeydew ranges from around 3\% to $10 \%$ W/W (e.g. Detrain et al., 2010; Völkl et al., 1999) while that of floral nectar and extrafloral nectaries ranges from 3\% to 25\% W/W (e.g. Engel et al., 2001; Gonzalez-Teuber and Heil, 2009; Heil et al., 2011). Thus, the feeding response curve of aphid-tending ants, such as $L$. niger, overlaps with the range of sugar concentrations that are produced by aphids and plants in their natural environment.

The exploitation of resources among ant consumers is based not only on the total amount of available sugars - but also on their carbohydrates composition. Sugars other than sucrose, glucose and fructose are common in honeydew, but rare in nectar which has a less complex sugar composition (Percival, 1961; Völkl et al., 1999). Furthermore, the sugar composition of honeydew varies in relation to several factors, including aphid species, host plant or level of tending activity (Fischer et al., 2005; Fischer and Shingleton, 2001; Völkl et al., 1999). One can assume that a higher sensitivity of scouts to one sugar offered by a certain resource might regulate the whole selection process, as well as the further exploitation of this resource by a given ant colony.
Here, we show that the feeding response of $L$. niger scouts differs in response to increasing amounts of a specific sugar.

Trehalose only induces a weak acceptance among ant workers, regardless of concentration. This sugar is rarely found in honeydew, but is often present in the haemolymph of insect prey (Friedman, 1985). The weak interest of $L$. niger in trehalose may be related to its feeding habit which, as an aphid tending species, only occasionally feeds on prey. In contrast, ants preferentially feed on the three main sugars (i.e. glucose, fructose and sucrose), which are present in both nectar (Engel et al., 2001; Percival, 1961) and honeydew (Detrain et al., 2010; Völkl et al., 1999). Likewise, ants are highly motivated to feed on aphid-biosynthesised melezitose, which is specifically excreted in honeydew. In these latter cases, feeding behaviour markedly increases with sugar concentration until maximum acceptance values are reached, which are the highest for sucrose and fructose.

Regarding the potential of a sugar to act as a phagostimulant, there are differences in concentrations at which feeding is first stimulated and at which the half of maximal feeding acceptances is reached.

The disaccharide sucrose was well ingested by ants at low molarities and had higher phagostimulating efficiency compared to the two monosaccharides. However, when expressed in mass concentration (i.e. by taking into account the number of saccharidic units), both the monosaccharides (fructose, glucose) and disaccharide (sucrose) had $\mathrm{EC}_{50}$ and TC values of the same order of magnitude. Therefore, for the three sugars that are the most abundant in honeydew and nectar, differences in feeding response threshold and in phagostimulating efficiency are primarily related to their energy content (i.e. their number of saccharidic units) rather than to the sugar type per se. From a physiological perspective, because all three sugars are able to cross the intestinal barrier of insects, and show high profitability in further metabolic processes with a positive effect on ant survival (Boevé and Wäckers, 2003; Turunen, 1985), the associated energetic return appears to be an important factor that shapes the feeding response and detection threshold of ant scouts.

Melezitose showed the highest efficiency to stimulate drinking (i.e. with the lowest $\mathrm{EC}_{50}$ and $\mathrm{TC}$ values). This result indicates that the sensilla receptors of ants have the strongest affinity for this trisaccharide, which is very efficient at stimulating a feeding response even with a small number of sugar molecules. Likewise, melezitose positively influences the frequency of trophallaxies and food sharing in the ant nest (Buffin et al., 2011). The informative value associated to a given sugar is thus another factor for which high sensitivity and quick feeding response by ants may be adaptive. This phenomenon occurs for sugars that are used by ants as a cue for the presence of a specific sugar producer. The high sensitivity of ants to aphid-biosynthesised melezitose confirms the key role played by this trisaccharide in the ant-aphid mutualism. A low feeding response threshold to small amounts of aphid-biosynthesised melezitose, when coupled with the onset of intense recruitment (Detrain et al., 2010), may speed up the exploitation and facilitate the monopolisation of aphid colonies that provide more productive spatio-temporally stable resources compared to nectar.

As confirmed by the present study, the feeding response profile of a given ant species is related to the expected energetic return and/or informative content associated to sugar resources. At a lower level, the feeding profile also varies among group members in relation with the division of labour in insect societies. In honeybees, differences in sucrose responsiveness correlate with individual tendencies to forage either for pollen or nectar (Page et al., 1998; Pankiw and Page, 1999; Pankiw et al.,2001). A relationship between sucrose responsiveness, behavioural specialisation, and appetitive olfactory learning has also been recently demonstrated 
in ants (Perez et al., 2013). Hence, further investigation about differences in taste sensitivity among nestmates of aphid-tending ant species is required to correlate individuals with task specializsation as nurses, foragers or aphid tenders, and to account for the partitioning of foragers among alternative resources (i.e. nectar, extrafloral nectar, honeydew and prey).

\section{Acknowledgements}

This project was financially supported by Fonds de la Recherche Fondamentale Collective (F.R.F.C.-F.N.R.S.) research projects (2.4600.09 and 2.4579.12). C. Detrain is Senior Research Associate at the Belgian National Fund for Scientific Research (FNRS).

\section{References}

Baker, H.G., Baker, I., 1973. Amino-acids in nectar and their evolutionary significance. Nature $241,543-545$.

Beattie, A.J., 1985. The evolutionary ecology of ant-plant mutualisms. Cambridge University Press.

Beckers, R., Deneubourg, J.L., Goss, S., 1993. Modulation of trail laying in the ant Lasius niger (Hymenoptera: Formicidae) and its role in the collective selection of a food source. J. Insect Behav. 6, 751-759.

Blüthgen, N., Fiedler, K., 2004. Competition for composition. Lessons from nectarfeeding ant communities. Ecology 85, 1479-1485.

Boevé, J.L., Wäckers, F.L., 2003. Gustatory perception and metabolic utilization of sugars by Myrmica rubra ant workers. Oecologia 136, 508-514.

Buckley, R., 1987. Interactions involving plants, homoptera, and ants. Annu. Rev. Ecol. Syst. 18, 111-135.

Buffin, A., Mailleux, A.C., Detrain, C., Deneubourg, J.L., 2011. Trophallaxis in Lasius niger: a variable frequency and constant duration for three food types. Insectes Soc. 58 (2), 177-183.

Detrain, C., Deneubourg, J.L., Pasteels, J.M., 1999. Decision-making in foraging by social insects. In: Detrain, C., Deneubourg, J.L., Pasteels, J.M. (Eds.), Information Processing in Social Insects. Birkhaüser Verlag, Basel, pp. 331-354.

Detrain, C., Verheggen, F.J., Diez, L., Wathelet, B., Haubruge, B., 2010. Aphid-ant mutualism: how honeydew sugars influence the behaviour of ant scouts? Physiol. Entomol. 35, 168-174.

Dussutour, A., Simpson, S.J., 2008. Carbohydrate regulation in relation to colony growth in ants. J. Exp. Biol. 211, 2224-2232.

Engel, V. Fischer, M.K., Wäckers, F.L. Völkl, W. 2001. Interactions between extrafloral nectaries, aphids and ants: are there competition effects between plant and homopteran sugar sources? Oecologia 129, 577-584.

Faribele, A., Josens, R., 2012. Sucrose acceptance threshold: a way to measure sugar perception in ants. Insectes Soc. 59, 75-80.

Fischer, M., Shingleton, A., 2001. Host plant and ants influence the honeydew sugar composition of aphids. Funct. Ecol. 15, 544-550.

Fischer, M.K., Völkl, W., Hoffmann, K.H., 2005. Honeydew production and honeydew sugar composition of the polyphagous black bean aphid, Aphis fabae (Hemiptera: Aphididae) on various host plants and implications for antattendance. Eur. J. Entomol. 102, 155-160.

Friedman, S., 1985. Carbohydrate metabolism. In: Gilbert, L.I., Kerkut, G.A. (Eds.), Comprehensive Insect Physiology, Biochemistry and Pharmacology. Pergamon Press, Oxford, pp. 43-76.

Gonzalez-Teuber, M., Heil, M., 2009. Nectar chemistry is tailored for both attraction of mutualists and protection from exploiters. Plant Signal. Behav. 4, 809-813.

Harder, L.D., 1986. Effects of nectar concentration and flower depth on flower handling efficiency of bumble bees. Oecologia 69, 309-315.

Heil, M., 2011. Nectar: generation, regulation and ecological functions. Trends Plant Sci. 16 (4), 191-200.
Hölldobler, B., Wilson, E.O., 1990. The Ants. Harvard University Press, Cambridge. Jackson, D.E. Châline N. 2007. Modulation of pheromone trail strength with food quality in Pharaoh's ant, Monomorium pharaonis. Anim. Behav. 74, 463-470.

Josens, R.B., Roces, F., 2000. Foraging in the ant Camponotus mus: nectar-intake rate and crop filling depend on colony starvation. J. Insect Physiol. 46, 1103-1110.

Josens, R.B., Farina, W.M., Roces, F., 1998. Nectar feeding by the ant Camponotus mus: intake rate and crop filling as a function of sucrose concentration. J. Insect Physiol. 44, 579-585.

Lanza, J., Smith, G.C., Sack, S., Cash, A., 1995. Variation in nectar volume and composition of Impatiens capensis at the individual, plant, and population levels. Oecologia 102 (1), 113-119.

Mailleux, A.C., Deneubourg, J.L., Detrain, C., 2000. How do ants assess food volume? Anim. Behav. 59, 1061-1069.

Mailleux, A.C., Deneubourg, J.L., Detrain, C., 2003. Regulation of ants' foraging to resource productivity. Proc. R. Soc. London, B 270, 1609-1616.

Nardone, E., Dey, T., Kevan, P.G., 2013. The effect of sugar solution type, sugar concentration and viscosity on the imbibition and energy intake rate of bumblebees. J. Insect Physiol. 59, 919-933.

Page, R.E., Erber, J., Fondrk, M.K., 1998. The effect of genotype on response thresholds to sucrose and foraging behavior of honey bees (Apis mellifera L.). J. Comp. Physiol. A. 182, 489-500.

Pankiw, T., Page, R.E., 1999. The effect of genotype, age, sex, and caste on response thresholds to sucrose and foraging behavior of honey bees (Apis mellifera L.). J. Comp. Physiol. A. 185, 207-213.

Pankiw, T., Waddington, K.D., Page, R.E., 2001. Modulation of sucrose response thresholds in honey bees (Apis mellifera L.): influence of genotype, feeding, and foraging experience. J. Comp. Physiol. A. 187, 293-301.

Paul, J., Roces, F., 2003. Fluid intake rates in ants correlate with their feeding habits. J. Insect Physiol. 49, 347-357.

Percival, M.S., 1961. Types of nectar in angiosperms. New Phytol. 60, 235-281.

Perez, M., Rolland, U., Giurfa, M., d'Ettorre, P., 2013. Sucrose responsiveness, learning success, and task specialization in ants. Learning Memory 20 (8), 417420.

Roubik, D.W., Buchmann, S.L., 1984. Nectar selection by Melipona and Apis mellifera (Hymenoptera: Apidae) and the ecology of nectar intake by bee colonies in a tropical forest. Oecologia 61, 1-10.

Stadler, B., Dixon, A.F.G., 2005. Ecology and evolution of aphid-ant interactions. Annu. Rev. Ecol. Evol. Syst. 36, 345-372.

Tinti, J.M., Nofre, C., 2001. Responses of the ant Lasius niger to various compounds perceived as sweet in humans: a structure-activity relationship study. Chem. Senses 26, 231-237.

Turunen, S., 1985. Absorption. In: Gilbert, L.I., Kerkut, G.A. (Eds.), Comprehensive Insect Physiology, Biochemistry and Pharmacology. Pergamon Press, Oxford, pp. $250-253$.

Vantaux, A., Van den Ende, W., Billen, J., Wenseleers, T., 2011. Large interclone differences in melezitose secretion in the facultatively ant-tended black bean aphid Aphis fabae. J. Insect Physiol. 57, 1614-1621.

Völkl, W., Woodring, J., Fischer, M., Lorenz, M.W., Hoffmann, K.H., 1999. Ant-aphid mutualisms: the impact of honeydew production and honeydew sugar composition on ant preferences. Oecologia 118, 483-491.

Wäckers, F.L., 2000. Do oligosaccharides reduce the suitability of honeydew for predatoand parasitoids? A further facet to the function of insect-synthesized honeydew sugars. Oikos 90, 197-202.

Wäckers, F.L., 2001. A comparison of nectar- and honeydew sugars with respect to their utilization by the hymenopteran parasitoids Cotesia glomerata. J. Insect Physiol. 47, 1077-1084.

Way, M.J., 1963. Mutualism between ants and honeydew-producing. Homoptera. Ann. Rev. Entomol. 8, 307-344.

Wilson, E.O., 1962. Chemical communication among workers of the fire ant Solenopsis saevissima (Fr. Smith) 1. The organization of mass-foraging. Anim. Behav. 10, 134-147.

Yao, I., Akimoto, S.I., 2001. Ant attendance changes the sugar composition of the honeydew of the drepanosiphid aphid Tuberculatus quercicola. Oecologia 128 36-43. 